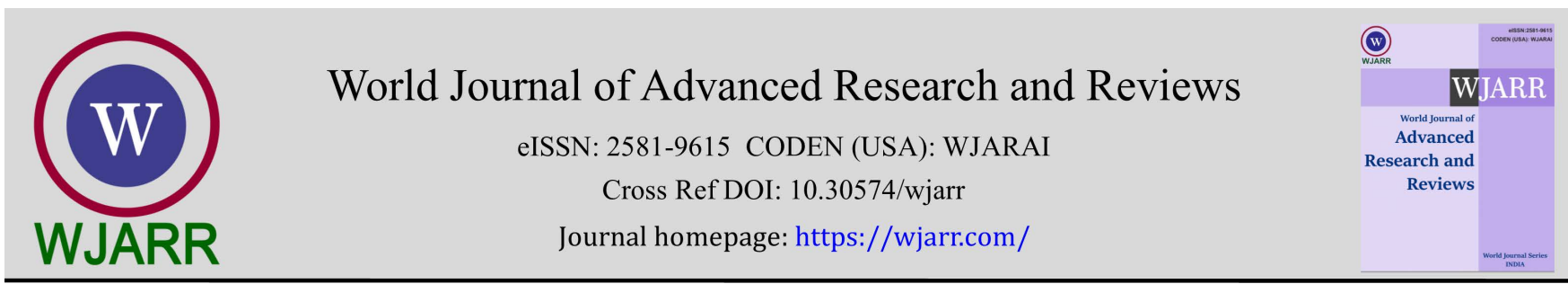

(REVIEW ARTICLE)

Check for updates

\title{
A note on the dynamics of food systems in Algeria: The example of the Ziban and the Souf
}

\author{
Salah Bouchemal * \\ RNAMS Laboratory, Institute of Urban Management Techniques, University of Oum El-Bouaghi, Algeria.
}

World Journal of Advanced Research and Reviews, 2021, 10(01), 048-055

Publication history: Received on 22 February 2021; revised on 26 March 2021; accepted on 28 March 2021

Article DOI: https://doi.org/10.30574/wjarr.2021.10.1.0124

\begin{abstract}
This work is about a note which records some results concerning a research undertaken in Algeria. It is part of a cooperation between several Mediterranean teams. Its objective is to report on current developments in agricultural practices on the environment and on the territories, in order to design conceptual scenarios that will draw profiles that can ensure sustainable food security in cities and the maintenance of biodiversity. Similarly, it will have another interest, it is to develop an exhaustive and homogeneous database on the western part of the Mediterranean basin. For Algeria, the studied areas are distributed on a biogeographical section, from the Mediterranean coast to the Sahara, that is to say, places sufficiently representative of the North-South ecological degradation and of the diversity of situations. The results reported in this note concern two Saharan areas, the Ziban and the Souf, as the final results of the research have not yet been achieved, since the project is still ongoing. In these two areas, agriculture in the past was limited to the traditional oasis system, just to ensure the subsistence of the inhabitants, but today, several factors have contributed to a revival of agriculture whose development is spectacular. Thus, the Ziban and the Souf have become very important food producing areas and even exporters of food products. However, it should be pointed out that this dynamic, if it is a source of innovation, it has negative consequences on the oasis heritage and on the environment.
\end{abstract}

Keywords: Food systems; Water; Ghout; environment; Ziban; Souf

\section{Introduction}

With this note, we wanted to deliver some results relating to a research, in progress, on the dynamics of food systems in Algeria. This research concerns our contribution to a research project whose objective is to answer the question relating to the impact of land use as a result from the human action on the environment and from practices of the actors of the territories (Bouchemal, 2018). In order to do this, it is necessary to assess the effects of the main current developments on the environment and to analyze and model the spatial interactions between the current dynamics of agricultural practices and natural environments at several scales in the Mediterranean Basin, with the aim of ensuring adequate food security in cities. The project also has another interest, that of creating an exhaustive and homogeneous database on the western part of the Mediterranean Basin (Southern Europe and Maghreb).

With regard to Algeria, we considered, on the basis of increased investigations, that it would be relevant to define the case studies according to a North-South section through which ecological degradation appears. For this country appears both as a transition zone between temperate and tropical climates and as a contact between Mediterranean mountainous garlands and African tabular surfaces. The mark, in the morphological landscape, of the climatic imprints of the quaternary, signs of a repeated swing between rainy and arid phases, gives even more value to this observation. Thus, the play of natural influences is at the origin of a veritable marquetry where plains, plateaus and mountains, dry and wet regions are juxtaposed. The environmental conditions are often difficult, but in order to take better advantage

\footnotetext{
${ }^{*}$ Corresponding author: Salah Bouchemal

RNAMS Laboratory, Institute of Urban Management Techniques, University of Oum El-Bouaghi, Algeria.
} 
of them, the populations have set up one or more production systems according to the North-South ecological degradation through which the Mediterranean climate, in Algeria and for the whole of the Maghreb, has been subdivided into several bioclimatic zones.

Thus, and from what has been stated, we have chosen four areas in Eastern Algeria for the implementation of the project in Algeria, places that are sufficiently representative of North-South ecological degradation and given the diversity of situations, but situations that together have two points in common: agricultural activities taking different modalities and rural areas that have become urban-rural interference spaces. The selected terrains present contexts that can be summarised as follows

- A coastal plain, that of Annaba (figure 1), which constitutes an agro-ecological area that has always been fertile. All market gardening are practised there, thanks to a relatively favourable climate, and cattle breeding is also present. However, the plain is threatened by urbanization and the setting up of industrial infrastructures, which are a factor of environmental degradation and one of the strongest manifestations of pollution.

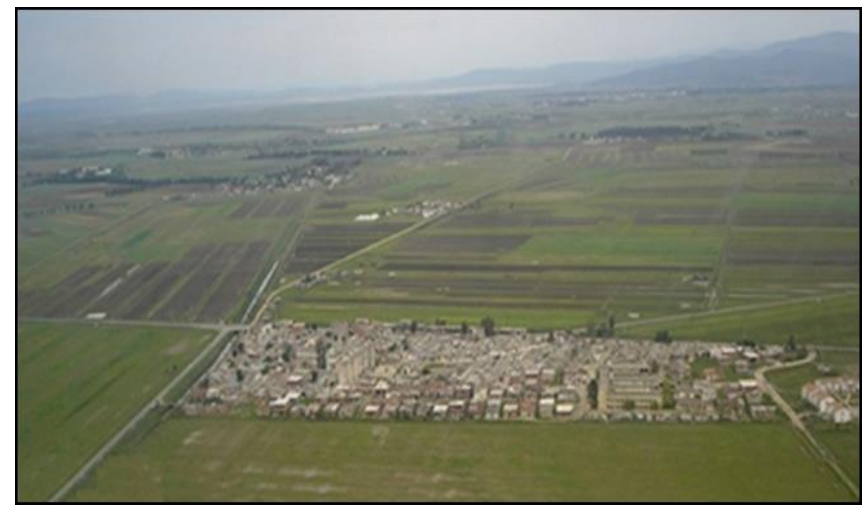

Figure 1 A sector of the Annaba plain (source : undated, anonymous)

- The El Eulma-Sétif-Aïn Arnat axis, in the Eastern High Plains (figure 2), where 400.000 inhabitants are concentrated and where cereal farming, intensive livestock farming and poultry farming predominate. In this area, agriculture is being undermined by an urban explosion, the repercussions of which are very worrying, particularly those concerning its sustainability and the issues relating to land tenure.

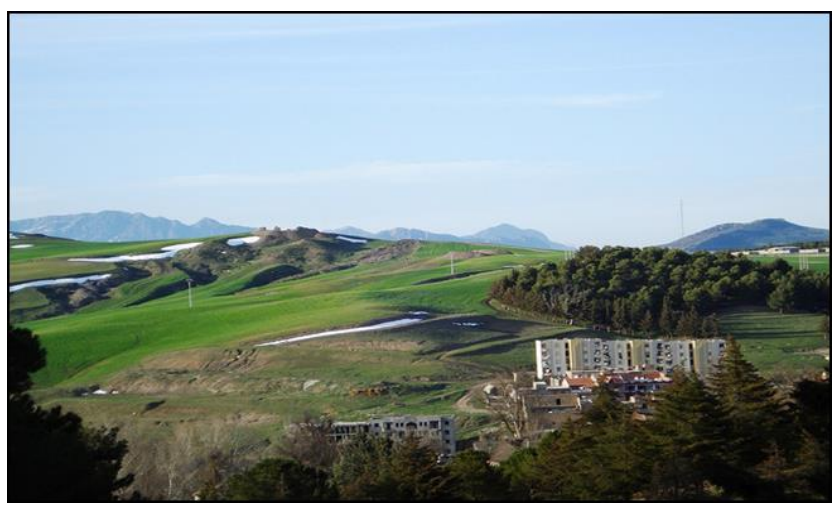

Figure 2 A sector of the El Eulma-Sétif-AïnArnat axis (source: undated, anonymous)

- The third area consists of two sectors in the north-east of the Sahara: the first is constituted by an oasis, in the Ziban, that of the Tolga palm grove, near Biskra (figure 3), and an adjacent zone, El Ghrous, where greenhouse gardens are meticulously cultivated in polyculture to constitute one of the most important regions for market garden products in Algeria (figure 4). The second sector is that of Souf, which has also become a very important feeding zone and exporter of agricultural products, but whose development is damaging to the traditional oasis ecosystem. Here and there, the environmental problems are acute, they are linked to the current dynamics of agricultural practices (drying up of the water table in the Ziban and rising water levels in the Souf). 


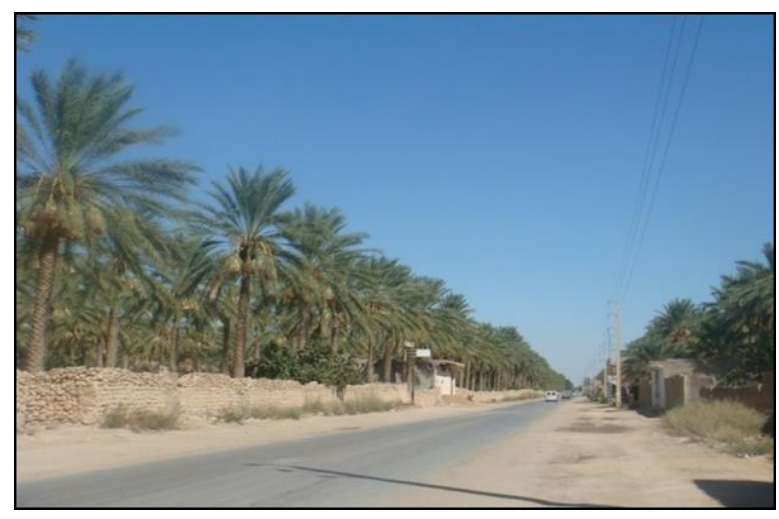

Figure 3 A palm grove in Tolga (Salah Bouchemal, 2019)

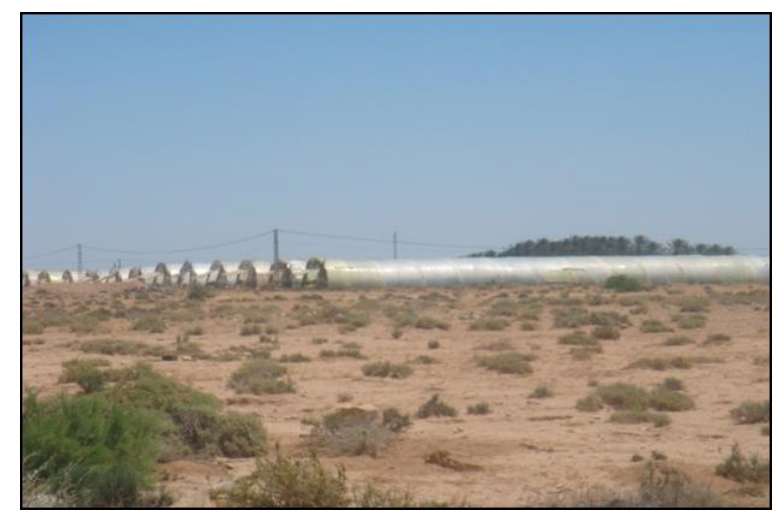

Figure 4 A landscape of cultures under plastic shelters in El Ghrouss (Salah Bouchemal, 2019)

\section{The dynamics of agro-systems in the Ziban and the Souf}

As the project is still in progress, we have not yet reached the final results of the research, but we are able to give an overview of the dynamics of the agro-systems in the Ziban and the Souf, two sectors where human organisations have taken shape through a socio-hydraulic system that for centuries has been able to adapt to the difficult conditions of the environment. In the past, agriculture was limited to the traditional oasis system where, in the shade of the date palm tree, several strata of crops evolved. Today, this system has difficulty surviving, due to several factors.

In the Ziban, mainly in the Tolga oasis, this situation is the consequence of a rapid and massive urbanization of the surroundings of the old palm groves, it tends to make a real conurbation emerge. It is also linked to the socio-economic spin-offs generated by the recent agricultural development of the surrounding areas. The Ziban is an old date producing region, where the land was once irrigated by springs gushing out of the foothills of the Zab mountain range, which are now relayed by boreholes drawing from abundant, semi deep water tables. Agriculture has been revived here since the 1980s with a revival of date palm cultivation thanks to new plantations around the old palm groves and also by the development of other land.

El Ghrouss, like many other places, is a perfect example of the particular development of agriculture in the Ziban. Here, the revival of date palm cultivation was very quickly supplanted by a spectacular development of greenhouse crops: market gardening in greenhouses as far as the eye can see, with more than 20.000 tunnels in standardised modules (50 $\mathrm{X} 8 \mathrm{~m}$ ) for this sector in 2018. A wide variety of crops are grown (tomatoes, peppers, cucumbers, artichokes, melons, watermelons...). These products are sold on the wholesale market of El Ghrouss which, every day, drains towards it, several hundred traders from the East as well as from the Centre and West of Algeria.

The creation of this market dates back to 1985, it belongs to the commune but is managed by a successful bidder. The control services are lax or even nonexistent, the sanitary service is not provided and the operators do not carry out any packaging. 
The buyers invest the market with a number of trucks ranging from 100 to 150 per day, and whose tonnage is between 2.5 and 5 tones, that is to say a volume of treated goods that hardly explains the derisory amount of a tender which amounts to 70.000.000 Dinars for a period of 3 years. The buyer loads directly from the seller's van but not without having to go through the owner of a scale, a service provider who receives 5 Dinars for a case of goods. Most often, producers turn to middlemen to sell their goods for a commission. Moreover, it is these middlemen who have a say in determining prices, but sometimes production is sold at the place of production. The buyers are mainly wholesalers, traders who serve retailers and raise the cost of the products. Their customer is made up of retailers, to whom they offer supply facilities, as they even deliver to homes.

The products put on sale on the market correspond to crops whose production is independent of the seasons, insofar as it is carried out at a time when it cannot be done in the open field, in the north of the country, as in the case of the tomato, which is found in overabundance in winter, when it cannot be grown in its traditional areas. The tomato of the Ziban sector reaches some 300.000 tones, that is to say nearly a third of Algeria's annual production. This type of tomato which does not find its competitor is very profitable, the price having reached, on the stalls, in February 2019,100 Dinars per kilogram, while in summer, when the tomato arrives from the openfield, prices fall considerably. From the middle of March, at the end of the winter tomato cycle, other types of crops are introduced, such as melons and watermelons, which are harvested long before the field tomato. But all of these crops, if they make fortunes, are obtained with very high yields thanks to the use of chemical fertilisers and pesticides, which can only be too dangerous for the environment and the consumer, because without the use of this type of input, the poverty of the sandy soil cannot be compensated for. By sinking only very little into the soil, the roots can only extract the bare minimum of nutrients. Moreover, tomatoes grown in the Ziban are not suitable for processing, because they are not profitable if they are concentrated. For example, one kilogram of concentrate requires 5 kilograms of fresh tomato, which means that it costs between 350 and 500 Dinars if the early tomato is used, as it is sold at 70 or 100 Dinars. For the concentrate, it is the field tomato that is requested, because it costs about 15 Dinars on average and less is invested for its transformation.

The development of greenhouse crops has been stimulated by two successive contributions, the 1983 law which ensures access to agricultural land ownership (APFA) for those who develop land and the National Agricultural Development Plan (PNDA) which finances those who develop agriculture (Bouchemal, 2020). Land has been allocated in ranges from 2 to 10 hectares according to potential. In many cases, however, land beneficiaries do not honour their commitments to the state that provides land and funding. As greenhouse cultivation is a tedious activity, these beneficiaries prefer to entrust the greenhouse to a manager or rent it. In total, a manager receives a quarter of the harvest, while a greenhouse is rented, during 2018, for about 300.000 dinars per year. The tenants and managers have a varied origin, they are mostly from market gardening sectors with an old reputation, such as Mitidja, at the gates of Algiers. The protected crops provide substantial gains for the producers. The latter very often call upon young workers. Thus, there is a significant presence of young people working the land, most of them are barely over 25 years old and some of them are 18,19 years old. In general, these young workers start working the land as labourers, then become sharecroppers, after having saved some income, which enables them to become tenants and finally owners. In most cases, the success of the farm work leads them to invest in the same activity in their region of origin or in other sectors.

According to our calculations, a greenhouse producing, on average, 11 quintals of tomatoes or 7 quintals of peppers, provides income equivalent to that of 20 palm trees producing high quality dates (deglet nour) with yields of 100 to 150 $\mathrm{kg} /$ tree. But the investments are higher in the first case than in the second. However, farmers tend to invest, initially and simultaneously, in both types of crops, while thinking of gradually reducing the number of greenhouses over time. For despite a very heavy volume of work and higher costs, greenhouse cultivation provides immediate income, whereas young palm plantations only start production after about ten years. The palm tree requires less effort, it is more profitable and the price of its product fluctuates less. In this way, it is thought that all urgent monetary needs will be met while waiting for the palm grove to be established, which will later constitute the farm's capital security.

As their whole, the Ziban are the archetype of a dynamic peasantry. The development of greenhouse crops, thanks to the contributions of the State and the Saharan climate, has made it the leading region for the production of early vegetables in Algeria. However, the multiplication of boreholes is not without weighing on the hydric potentialities, because the water tables are today subject to a worrying drawdown. But it is in the Souf, and more than elsewhere, that the phenomenon is best felt. In this region, irrigation is based on the water table. The traditional cultivation system consists of planting palm trees at the bottom of large craters, called ghouts in vernacular terms, where the water is drawn directly from the water table, since it is the tree that goes towards it. This method allows farmers to avoid all the irrigation burdens they face in other arid regions. The ghouts are dug into the sand with strenuous labour, and they are constantly maintained to avoid silting up. Figure 5 is an example of a ghout in the Souf sector. At the front of the figure, the surface that overhangs the ghout is bordered by an earthen wall, the tabia, which serves to prevent the advance of sand. This surface includes a field of young palm trees and a plot cultivated in market gardening, the whole is irrigated 
with drip. Figure 6 represents a sand carrier to whom a tribute is paid so as not to forget his considerable work in the creation of a remarkable secular heritage.

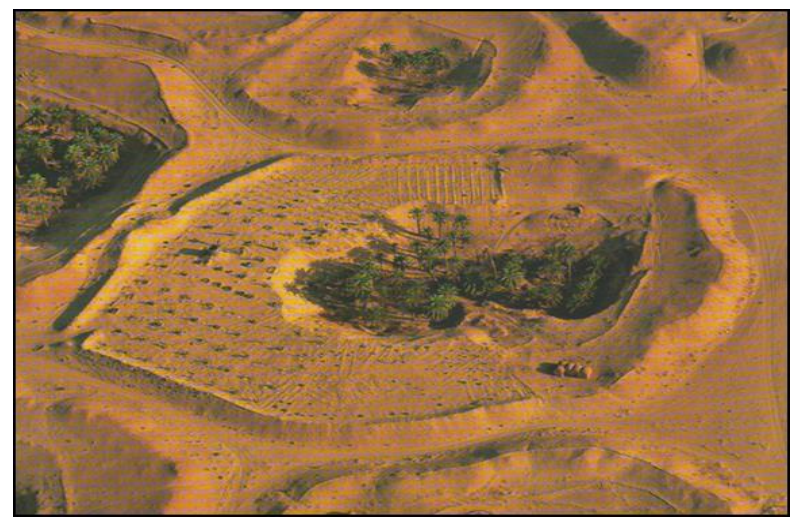

Figure 5 An example of ghouts in the Souf sector (source : Yann Arthus-Bertrand, undated)

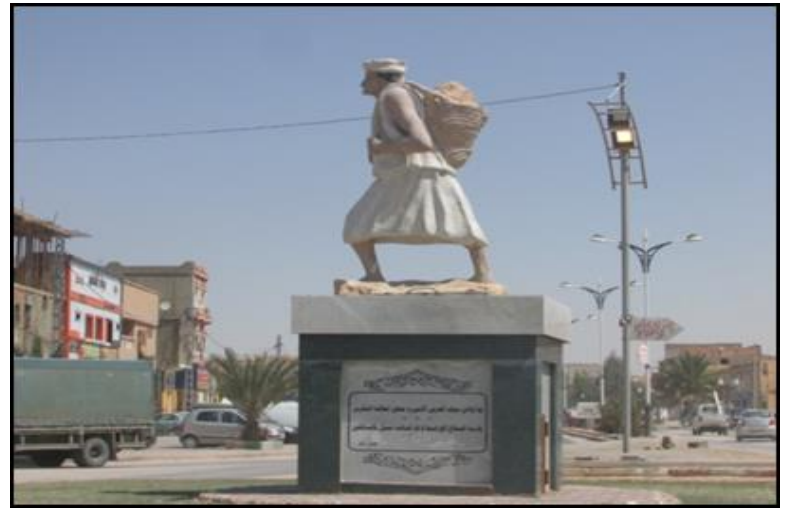

Figure 6 A statue representing a sand carrier in El Oued in the Souf sector (Salah Bouchemal, 2017)

This original and single irrigation system is adapted to the difficult conditions of the natural environment of the Souf. However, because it is totally dependent on the level of the water table, it is considered precarious and doomed to disappear, even if in some places there is no hesitation in renewing the experience of the ancients. In addition, today there are only 472 functional ghouts, whereas 4 or 5 decades ago there were 9792 ghouts, and this number will be even smaller in the short term. Moreover, when the water table rises or falls, it threatens the palm trees, either by flooding or by drought. This poses the problem of a probable agro-ecological disaster, following the overexploitation of groundwater by massive and rapid urbanization or by new forms of agricultural land development (Khezzani, Bouchemal, Hallis, 2016; Khezzani, Bouchemal, 2018; Bouchemal, 2019). Figure 7 is an illustration of the phenomenon of the rise of the water table in an old ghout, due to new forms of agricultural practices. Figure 8 illustrates the phenomenon of rising water in an old ghout due to urbanization.

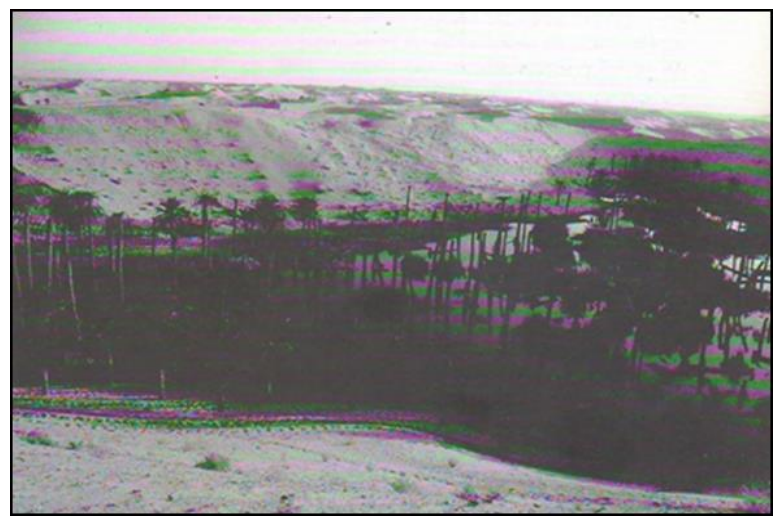

Figure 7 A ghout flooded by the water table and invaded by reeds in the Souf sector (source: Marc Côte, 2006) 


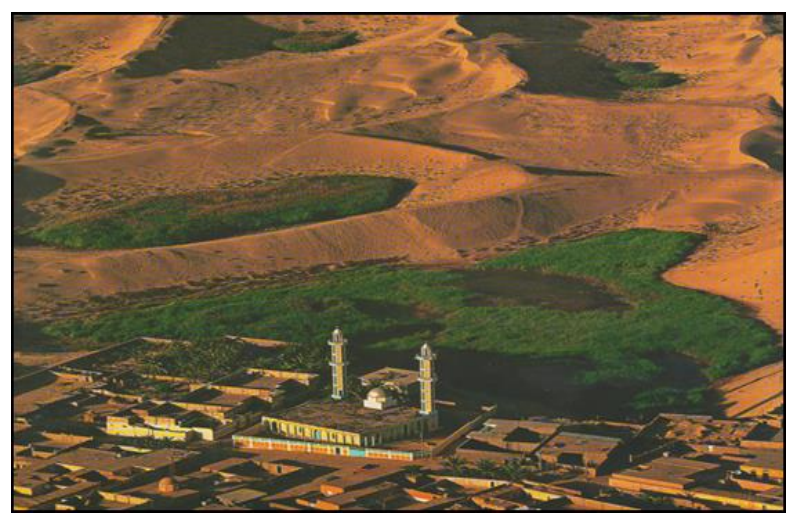

Figure 8 A new district of the city of El Oued whose existence is at the origin of the rise of the water table at the level of old ghout sand a vegetation that will give birth to reeds (source : Yann Arthus-Bertrand, undated)

The new forms of agricultural work are based on intensification through the increased development of market gardening and fruit crops in the open field for marketing. This agricultural system, which requires ever-increasing consumption of water resources, was unknown in the past, and also originated in the land agricultural ownership law of 1983 (APFA) and the PNDA funds. In this type of agricultural development, the crops do not need the cover of the palm trees for their protection, as it is only necessary to install windbreaks to repel the winds and reduce evapotranspiration (figure 9).

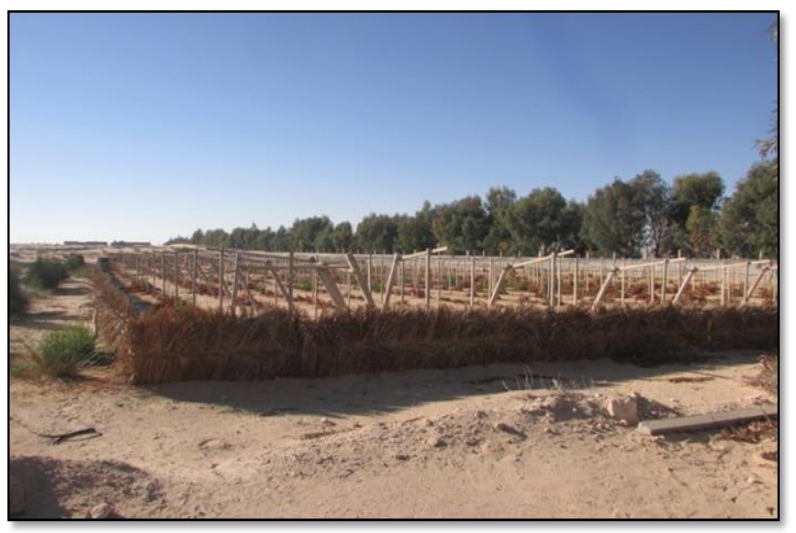

Figure 9 An example of a crop protected by a windbreak in the Souf sector (Salah Bouchemal, 2018)

In the Souf, protected crops are also present, but they occupy only a minimal part of the useful agricultural area. However, it is worth noting the importance of potatoes, grown in openfields, which were non existent in the early 1990s, whereas during the 2016-2017 agricultural season, they occupied an average area of almost $80 \%$ of that of market garden crops (35.000 hectares).

The development of this sector has made Souf the leading producer of this type of crop in Algeria, with around $25 \%$ of the country's total production, and it is also the main exporter of this product. Great progress has also been made in the production of winter tomatoes, so much so that in Magrane, near El Oued, the most important town in the region, a wholesale market has been set aside for the sole purpose of trading in this product, and we were able to observe that this commercial structure attracts a large number of traders from several regions of the country every day.

In the Ziban and the Souf, irrigation is the only means on which new forms of agricultural development are based. It is practised through the drip and pivot system. Drip irrigation is more water efficient and requires less financial outlay. The pivot is used for the irrigation of potato plots in the Souf (figure 10). Here, farmers irrigate with small pivots made by local craftsmen. This type of pivot replaced the conventional large pivots introduced by the government, as they were considered expensive and did not meet the needs of small and medium producers, mainly in terms of the size of the plot to be irrigated. 


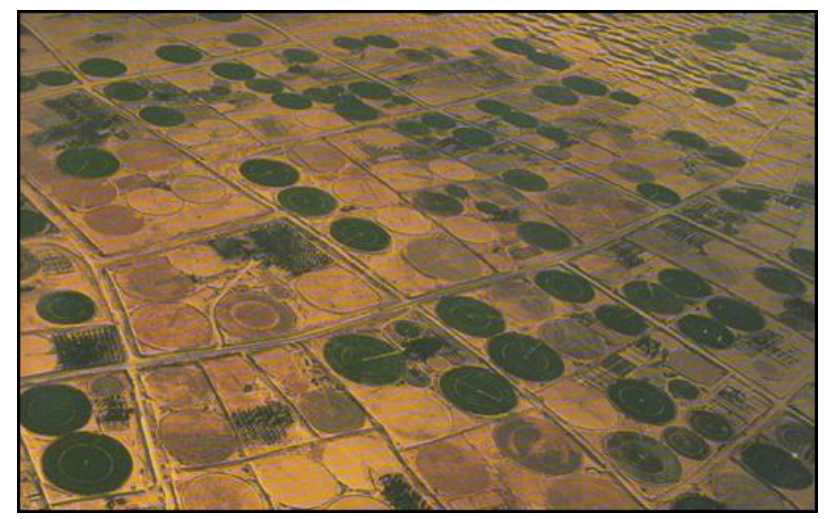

Figure 10 The brand of the pivot in the Souf sector (source: Yann Arthus-Bertrand, undated)

To finish this note, we would like to point out that we have only presented a few of the results concerning the treatment of the problem of our research, and they are far from being exhaustive, because there are other aspects than we have addressed, such as the daily life of farmers to highlight the problems they face and their relationship with management structures, and because we cannot deliver everything in a simple note, everything will obviously be recorded in articles for publication, especially since the work on the plain of Annaba and the axis El Eulma-Setif-AinArnat are not yet completed.

\section{Conclusion}

In this note, we have highlighted the dynamics of agricultural practices in two regions of the Algerian Sahara. The transition from subsistence agriculture to market agriculture has been made possible by a policy that has proven its worth, since date palm cultivation has been supplanted by the practice of market gardening and fruit crops on a large scale, and because its success makes it possible to meet the needs of several regions of Algeria, in addition to the export of certain products. This form of agriculture is, however, dependent on irrigation, which requires a large consumption of water, hence the overexploitation of this resource, which is also highly coveted by a strong urbanization, which, in the Souf, jeopardizes the survival of the ghout system. The progress of this research will allow us to develop strategies that we will recommend to alleviate the problems of water for a sustainable agricultural development that would preserve the oasis heritage and the environment.

\section{Compliance with ethical standards}

\section{Acknowledgments}

I would like to thank all the people who welcomed us to the study sites and who were willing to answer our questions, farmers and officials at the level of the agricultural services of Biskra and El Oued. I would also like to thank the members of my research team, the DIVERCROP project for Algeria.

\section{Disclosure of conflict of interest}

The research project in question is called DIVERCROP. It is part of a cooperation between several countries of the Mediterranean Basin and is part of ARIMnet 2 (Agricultural Research In the Mediterranean Network). For Algeria, it is under the responsibility of the General Directorate of Scientific Research and Technological Development (DGRSDT). The financial side is managed by the Biotechnology Research Center of Constantine (CRBt). ARIMNet 2 is a network of agencies for agricultural research in the Mediterranean (www.arimnet2.net). Its actions are funded by the European Union under the Seventh Framework Program for Research, Technological Development and Demonstration.

The text is strictly personal, as well as the data processing. Some elements of the field surveys are the contribution of the members of the DIVERCROP team for Algeria: Salah BOUCHEMAL, Abdelkader KHIARI, Nacerdine CHIBANE, Bachir KHEZZANI and Lyes TAÏB. 


\section{References}

[1] Salah BOUCHEMAL and al.: The implementation of the DIVERCROP project in Algeria. Conferences Series. 3rd Global Food Security and Sustainability Conference (Theme: Secure Today, Feed Tomorrow), New York (USA) May 21-22, 2018.

[2] Salah BOUHEMAL: The Water Use in Agriculture in the Algerian Central Sahara: What Future? In: United Journal of Agricultural Science and Reserach. 2020; V1(2): 1-5.

[3] Yann ARTHUS-BERTRAND et al.: Algérie vue du ciel. Éd. Éditions de la Martinière. 2011; 336.

[4] Bachir KHEZZANI, Salah BOUCHEMAL, Youcef HALLIS: Some agricultural techniques to cope with the fluctuation of the groundwater level in arid environments: case of the Souf oasis. Journal of aridland agriculture. 2016.

[5] Bachir KHEZZAN, Salah BOUCHEMAL: Development and Conservation of Water Resources for Agriculture in an Arid Environment: A Case Study of the Souf Oasis (Algerian Sahara). Annals of Arid Zone. 2018; 57(1\&2): 1-11.

[6] Salah BOUCHEMAL: New forms of agricultural development in the Algerian Sahara and their impact on water resources and the environment. 10th Academic International Conference on Multidisciplinary Studies and Education -A.ICMSE 2019 - Martin Conference Center at Harvard University, Boston USA. 23rd-25th September 2019.

[7] Marc CÔTE: Si le Souf m'était conté. Comment se fait et se défait un paysage. Média-Plus, Constantine. 2006; 135. 